\title{
SSE 2015: SOCIETY ACCEPTS THE SINGLE STATE EXAMINATION
}

\author{
T.Klyachko
}

One of the major developments in the Russian education system has remained practically unnoticed: after more than a decade of struggle against SSE, society effectively accepted it at last. The Single State Examination in 2015 was passed practically unnoticed by Russia's population. This year, no serious violations or leaks of knowledge assessment materials occurred during the SSE.

One of the major developments in the Russian education system took place without causing a ripple in public opinion: after more than a decade of struggle against the SSE, society effectively accepted it at last. The Single State Examination in 2015 was passed unnoticed by Russia's population. The secondary school graduates and their parents were certainly in a state of anxiety, but this is normal for any examination on the outcome of which a young person's future depends. Prior to the introduction of the SSE, a similar state of anxiety was always associated with secondary school graduation exams, and then with the entrance exams for admission to higher educational establishments (HEE). Some leaks of KAM (knowledge assessment materials) did occur, but these were few, and as attempts to cheat at examinations have always been part of their normal practice, the response to these facts was weak: contrary to what had happened in the previous years, this time there were no major mass-scale leaks. As said Deputy Head of the Federal Service for Supervision in the Sphere of Science and Education (Rosobrnadzor) Anzor Muzaev: 'The processing of the results is not over yet, but it can already be said that no serious violations or leaks of knowledge assessment materials occurred during the SSE, and there is not a single examinations site where any anomalous results were reported ${ }^{\prime \prime}$.

According to data released by the Federal Institute for Pedagogical Measurements (FIPI), over the period of this year's SSE, the hotline received '64 telephone calls concerning the issues of evaluation of test results based on KAM and the correctness of filling up the examination forms. More than 200 messages came to the e-mail address provided, on the issues of proper formalization of answers to the questions offered at the examinations, filling up the examination forms, and the grading process and the appellate procedure'2.

As demonstrated by Rosobrnadzor's data, 'during the main period of the Single State Examination ... the SSE

1 See http://www.obrnadzor.gov.ru/ru/press_center/news/ index.php?id_4=4916

2 See http://www.obrnadzor.gov.ru/ru/press_center/news/ index.php?id_4=4951 hotline received more than five thousand telephone calls. In addition, over the same period, more than two thousand messages were received via e-mail. The principal questions had to do with the way the results were generated, and especially the organization of the SSE, the addition of supplementary examination subjects of choice, and the rules for filing appeals and for entering higher educational establishments' ${ }^{3}$.

This state of affairs points to a well-organized SSE procedure, and to the fact that it has become a wellrun routine.

So, the simple measures designed to introduce proper order into the SSE procedure that had been taken in 2014 have resulted in society's belief in the objectivity of the state examinations, and in the acknowledgement of its benefits: the one-time examination procedure (which combines secondary school graduation exams and entrance exams to higher educational establishments), the ease of submitting the necessary documents to a higher educational establishment, and the broader range of specialties (or fields of study) available in the framework of higher education curricula (5 higher educational establishments and 3 fields of study (or specialties)).

Secondary school teachers were mollified by the return of literary composition, which has now become once again part of the examination: they believe that as a result of this, the subjects Russian Language and Literature have gained significant prestige in the eyes of the public and school graduates alike. It is another matter that this measure will have no real impact on the actual literacy level of the young generations, or produce any effect in terms of the young people's ability of critical thought and power of argumentative verbal expression. The degradation in Russian language skills had started long before the introduction of the SSE and the reestablishment of literary composition as one of the necessary components of the Single State Examination procedure, and this trend, regretfully, cannot be reversed.

3 See http://obrnadzor.gov.ru/ru/press_center/news/index. php?id_4=4931 
One more measure that reconciled secondary school teachers with the SSE and was positively estimated by higher educational establishments is the subdivision of the examination in Mathematics into a basic and advanced levels. Now those secondary school graduates who do not intend to enter those higher educational establishments where Mathematics is a major subject may take this examination at the basic level, while those who plan to make it their core specialty will take the advance version. It would be logical to apply this rule also to the Russian Language examination: those who are going to enter the higher educational establishments specializing in the humanities must take this exam at an advanced level.

If the choice of Biology, Physics, Chemistry, etc. as an examination subject for the SSE is to be considered as the manifestation of a secondary school graduate's intention to continue his or her studies in that particular field, these should also be treated as major subjects.

In this connection it will be feasible to arrange the SSE procedure as follows: those young people who intend to go on to a higher educational establishment must pass examinations in two subjects at an advanced level, and one examination at a basic level. This means that the examination scores acceptable for entry to higher educational establishments must also be altered. In 2015, the relevant scores ('cutoff scores') were set as follows (Table 1).

\section{MINIMUM SCORES IN DIFFERENT SUBJECTS SUFFICIENT FOR ENTERING HIGHER EDUCATIONAL ESTABLISHMENTS IN 2009-2015}

\begin{tabular}{|c|c|c|c|c|c|}
\hline Subject & 옴 & 음 & 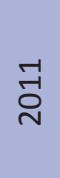 & 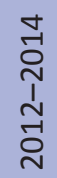 & $\stackrel{\text { ำ }}{\stackrel{0}{0}}$ \\
\hline Social Science & 39 & 39 & 39 & 39 & 42 \\
\hline Russian Language & 37 & 36 & 36 & 36 & 36 \\
\hline $\begin{array}{l}\text { Informatics and Computer } \\
\text { Technologies }\end{array}$ & 36 & 41 & 40 & 40 & 40 \\
\hline Biology & 35 & 36 & 36 & 36 & 36 \\
\hline Geography & 34 & 35 & 35 & 37 & 37 \\
\hline Chemistry & 33 & 33 & 32 & 36 & 36 \\
\hline Physics & 32 & 34 & 33 & 36 & 36 \\
\hline Literature & 30 & 29 & 32 & 32 & 32 \\
\hline History & 30 & 31 & 30 & 32 & 32 \\
\hline Mathematics & 21 & 21 & 24 & 24 & 27 \\
\hline English Language & 20 & 20 & 20 & 20 & 22 \\
\hline German Language & 20 & 20 & 20 & 20 & 22 \\
\hline French Language & 20 & 20 & 20 & 20 & 22 \\
\hline Spanish Language & 20 & 20 & 20 & 20 & 22 \\
\hline
\end{tabular}

Source: http://www.edu.ru/abitur/act.59/index.php

Higher educational establishments may set on their own the minimum scores for the major subject required for enrolment in Bachelor Degree programs (in some cases - Specialist Degree programs). The minimum scores shown in Table 1 mean that no applicants with scored below these values can be accepted by higher educational establishments.

Sergey Kravtsov, Head of Rosobrnadzor, explained that the basic level in Mathematics was assessed by applying the 1-5 scale, and the average score amounted to 3.95.

The 27-point score for Mathematics in Table 1 is the acceptable minimum for those who took the examination at the advanced levels. But is appears that those higher educational establishments where Mathematics is a major subject cannot accept applicants who had gained only 27 points, as this effectively means that they have failed their examination. This score is too low for a prospective student who aspires to specialize in technical sciences. And many higher educational establishments in the situation of 'demographic slump' cannot get an appropriate number of properly educated students, and so have to put up with such a low score.

The situation with regard to minimum scores in the other subject that can be treated as 'major' ones is slightly better: the government allows higher educational establishments to enroll applicants with scores of 3 and 3- (based on the 1-5 scale), or with 32-36 points. And the minimum scores for foreign languages are exceedingly low -22 points.

At the same time, in 2015 the average scores in many of the subjects included in the SSE demonstrated an upward trend. The average score for Russian Language was 65.9 points, for Literature -57.1 points, for Mathematics (advanced level) - 50.9 points; the average score for Physics had increased from 45 to 51 points, for Chemistry it rose to 57 points.

It should be reminded that in 2014, due to the introduction of tougher control, the average SSE scores in all the subjects significantly dropped (Table 2).

Table 2

AVERAGE SCORES IN SSE SUBJECTS IN 2013-2015

\begin{tabular}{|l|c|c|c|}
\hline \multicolumn{1}{|c|}{ Subject } & 2013 & 2014 & 2015 \\
\hline Mathematics & 50 & 40 & 50.9 \\
\hline Physics & 55 & 46 & 51.1 \\
\hline Chemistry & 69 & 56 & 57.1 \\
\hline Biology & 59 & 54 & 53.6 \\
\hline Geography & 58 & 53 & 53 \\
\hline Informatics and Computer & 63 & 57 & 54 \\
\hline Technologies & 73 & 61 & 65.9 \\
\hline English Language & 56 & 46 & 47.1 \\
\hline History & 60 & 53 & 58.6 \\
\hline Social Science & 60 & 54 & 57.1 \\
\hline Literature & 64 & 63 & 65.9 \\
\hline Russian Language & & &
\end{tabular}

Source: Federal Service for Supervision in the Sphere of Science and Education (Rosobrnadzor). 
While the decline of the average test score in 2014 on 2013 had been caused by two factors - tougher control (objective reason) and the psychological stress associated with the SSE (a subjective reason), the upward movement of the average test score in 2015 can be explained, it seems, only by the absence of the excessive stress factor during the SSE (it had been known in advance that the control procedure would be tough, and so those taking the exam were no longer susceptible to the effect of that factor). At the same time, it can hardly be believed that the quality of secondary school education per se could have had significantly improved over the course of one year. It should also be noted that the average test score for
Biology continued its decline, while that in Geography remained at the same level as in 2014 . However, the significant growth demonstrated by the average test scores for Physics (by 5.1 points) and Social Science (by 5.6 points) is somewhat alarming, because these are the major subjects for those higher educational establishments that specialize in technologies and engineering (Physics) and socioeconomic studies (Social Science) respectively.

In 2015, the priorities in the choice of optional examination subjects were distributed as follows: Social Science was chosen by $51.2 \%$, Physics - by $22 \%$, History - by $20 \%$, and Biology - by $17.4 \%$ of the SSE participants. 